\section{THU0115 NOCTURNAL MELATONIN SERUM LEVEL RHYTHM IN RHEUMATOID ARTHRITIS}

${ }^{1} \mathrm{~A}$ Sulli, ${ }^{2} \mathrm{GJ}$ Maestroni, ${ }^{1} \mathrm{C}$ Pizzorni, ${ }^{2} \mathrm{E}$ Hertens, ${ }^{1} \mathrm{C}$ Craviotto, ${ }^{1} \mathrm{~A}$ Bisso, ${ }^{1} \mathrm{C}$ Prete, ${ }^{1} \mathrm{M}$ Grosso, ${ }^{1} \mathrm{M}$ Briata, ${ }^{1} \mathrm{~B}$ Seriolo, ${ }^{1} \mathrm{M}$ Cutolo. ${ }^{1}$ Division of Rheumatology, Department of Internal Medicine, University, Genova, Italy; ${ }^{2}$ Istituto Cantonale Di Patologia, Center for Experimental Pathology, Locarno, Switzerland

\subsection{6/annrheumdis-2001.992}

Background The pineal hormone melatonin (MLT) exerts a variety of effects on the immune system. MLT activates Th1 lymphocytes and monocytes; moreover MLT enhances the production of inflammatory cytokines, like IL-1, IL-6, IL-12 and TNFa, as well as nitric oxide production.

Objectives Several symptoms of rheumatoid arthritis (RA), i.e. morning gelling, stiffness and swelling, are more evident in the early morning and might be related to the neuroimmunomodulatory effects exerted by MLT on synovitis. On the other hand, it is well known that MLT reaches its physiological serum peak level during the first hours of the morning.

Methods Nocturnal MLT serum levels ( 8 pm, 12 pm, 2 am, 4 am, 6 am, 8 am o'clock) were evaluated in ten RA patients (pts) (mean age $57 \pm 13 \mathrm{SD}$ ys) and in six healthy controls (cnts) (mean age $50 \pm 18$ SD ys). RA pts were taking only nonsteroidal antiinflammatory drugs and the mean disease duration was $4 \pm$ 2 SD ys. MLT assay was performed by RIA and statistical analysis was carry out by nonparametric tests.

Results MLT serum levels at $8 \mathrm{pm}$ and 8 am o'clock resulted higher in RA pts than in cnts $(\mathrm{p}<0.05)$. The differences were more evident in the older RA pts (age $>60 \mathrm{ys}$ ) when compared to the younger ones (age $<60 \mathrm{ys}$ ). In both RA pts and cnts, MLT progressively increased from 8 o'clock pm to the first hours of the morning, reaching the peak level that gradually decreased $(p<0.02)$. However, MLT serum level reached the peak at least three hours before in RA pts than in cnts $(\mathrm{p}<$ 0.05); subsequently, in RA pts, MLT concentration showed a plateau lasting two-three hours. After 2 am o'clock MLT levels decreased similarly in both RA pts and cnts. MLT levels progressively decreased with ageing in all subjects; nevertheless, MLT serum levels resulted significantly lower only in RA pts at 4 am and 6 am o'clock $(\mathrm{p}<0.05)$.

Conclusion The results of this study confirm the existence of a nocturnal rhythm of MLT also in RA pts, with the peak level in the early morning. However, RA pts showed higher mean MLT serum levels, that reached earlier the peak of concentration, and maintained the high levels for longer time when compared to cnts. The imbalance between cortisol serum levels (notably lower in RA pts) and MLT serum levels (higher in RA pts) might explain several clinical aspects related to the neuroimmunomodulatory effects on RA synovitis, such as morning gelling, stiffness and swelling.

\section{THU0116 AUTOANTIBODIES TO VASOACTIVE PEPTIDES AND ANGIOTENSIN-CONVERTING ENZYME IN PATIENTS WITH RHEUMATOID ARTHRITIS}

${ }^{1}$ ML Stanislav, ${ }^{1}$ RM Balabanova, ${ }^{2}$ MA Myagkova, ${ }^{2}$ TV Abramenko, ${ }^{3}$ OA Kost, ${ }^{3}$ Il Nikolskaya, ${ }^{3} \mathrm{EV}$ Garats. 'Department of the Correction of Autoimmune Disorders, Institute of Rheumatology of RAMS, Moscow; ${ }^{2}$ Department of Immunology, Institute of Physiologic Active Substances of RAS, Chernogolovka; ${ }^{3}$ Chemical Faculty, Moscow Lomonosov State University, Moscow, Russia

10.1136/annrheumdis-2001.993
Background Low levels of autoantibodies (AAb) are in fact a normal feature of a healthy immune response. The distinction between pathological and natural AAb is not well understand.

Objectives To study the levels AAb specifically reacting with angiotensin-converting enzyme (ACE) and endogenous vasoactive mediators in sera patients with rheumatoid arthritis (RA) and healthy control group.

Methods We tested sera from 19 patients with RA, 12 pts had extra-articular manifestations, 7 pts had only joint damage. The patients were compared with 10 healthy donors. Solid- phase enzyme immunoassay was used to examine the levels of IgM $\mathrm{AAb}$ to $\mathrm{ACE}$ prepared from human kidney tissue and AAb to low-molecular peptides - bradykinin (BK), angiotensin II (AII) and vasopressin (VP).

Results Analysis of IgM AAb to vasoactive peptides showed a significant increase account $\mathrm{AAb}$ to bradykinin (BK) in sera from RA patients compared to donors $(p=0,0074)$. The highest value of $A A b$ to $B K$ were observed in RA patients without extraarticular features. Level of AAb to BK correlated with CIC, joint score $(p<0,05)$. Significant discrepancies between levels AAb to AII and VP in RA pts and donors have not been revealed. Level of AAb to AII correlated negative with ERS ( $\mathrm{r}=-0,464, \mathrm{p}<$ $0,05)$. Amount AAb to ACE was increasing in RA patients, but the differences were not significant.

Conclusion The biological effects of AAb to vasoactive peptides and ACE are unknown. The possible role of $\mathrm{AAb}$ to $\mathrm{BK}$ in the pathophysiology of joint inflammation requires careful consideration.

\section{THU0117 THE BIAS FOR TH1 DIFFERENTIATION OF RHEUMATOID ARTHRITIS T CELLS IS CHARACTERISTIC OF MEMORY BUT NOT OF NAIVE T CELLS}

${ }^{1}$ A Skapenko, 'I Wendler, ${ }^{2} \mathrm{PE}$ Lipsky, ${ }^{1} \mathrm{JR}$ Kalden, ${ }^{1} \mathrm{H}$ Schulze-Koops. 'Department of Internal Medicine III, University of Erlangen-Nuremberg, Erlangen, Germany; ${ }^{2}$ NIAMS, NIH, Bethesda, USA

\subsection{6/annrheumdis-2001.994}

Background Rheumatoid arthritis (RA) is likely to be driven by activated Th1 cells. In contrast, Th2 cells and their cytokines, in particular IL-4, are rarely found in RA.

Objectives To determine whether memory or naive $\mathrm{CD} 4^{\text {pos }} \mathrm{T}$ cells in RA manifest an intrinsic bias for Th1 differentiation.

Methods Th differentiation was assessed in an ex vivo cell culture system in $\mathrm{CD}^{\text {pos }}{ }^{\text {, CD45RA }}{ }^{\text {pos }}$ (naive) and CD45RO pos (memory) $\mathrm{T}$ cells isolated from the peripheral blood from patients with active, early RA (mean disease duration $<7$ months) who had never been treated with disease modifying anti rheumatic drugs or corticosteroids. The phenotype of freshly isolated and effector cells was determined by flow cytometrical analysis of cytoplasmic cytokines.

Results Th2 effectors could be induced from memory T cells in all healthy controls by stimulation with anti-CD28 and IL-4 but in only one third of the RA patients. Priming conditions that were optimal for the differentiation of Th2 effectors from memory T cells, e.g. priming with anti-CD28 and IL- 4 in the absence of TCR-ligation, did not result in Th2 differentiation from resting naive $\mathrm{T}$ cells in any individual. In contrast to memory $\mathrm{T}$ cells, however, Th2 cells could be induced from naive $\mathrm{T}$ cells in all healthy donors and in all RA patients by priming with anti-CD3 in the presence of anti-CD28.

Conclusion CD4 ${ }^{\text {pos }}$ memory $\mathrm{T}$ cells from the majority of patients with early RA manifest a deficiency in the capacity to 